\title{
Analysis of Proportion of Possession of Tourism Income in Tertiary Industry in Hainan Province based on DDD
}

\author{
Ming Liu ${ }^{1, a}$, Hongxu Wang ${ }^{2, b}$, Youming Li, ${ }^{3, c}$, Xuebing Huang ${ }^{4, d}$ \\ ${ }^{1}$ College of Computer Engineer, Hainan Tropical Ocean University, Sanya, 572022, China \\ ${ }^{2}$ Hainan Tropical Ocean University, Sanya, 572022, China \\ ${ }^{3}$ College of Tropical Biology and Agronomy, Hainan Tropical Ocean University, Sanya, 572022, \\ China \\ ${ }^{4}$ School of China and Austria, Hainan Tropical Ocean University, Sanya, 572022, China \\ aemail:liumm2001@163.com, bemail:whx16233@126.com, 'email:youmingli@outlook.com, 'email: \\ pub.huang@qq.com
}

Keywords: Fuzzy Time Series Forecasting Model; DDD; Difference; Difference in Difference; Tertiary Industry

\begin{abstract}
A fuzzy time series forecasting model-DDD was proposed based on difference and deifference in difference in paper. Prportion of tourism revenue in tertiary industry during 2005-2015 in Hainan province. Results of DDD would provide useful help for the development and planning of tourism in some departments in Hainan province. In addition, a new model proposed was a beneficial supplement for the solving of time series forecasting.
\end{abstract}

\section{Introduction}

Fuzzy set theory was proposed by Zahde in 1965 and it has been a powerful tool for resolving the problem of uncertainty [1]. Song et al[2][3][4] proposed firstly fuzzy time series forecasting model in 1993 and analyzed the prediction of enrollment in University of Alabama during the 1971-1992 period. Other authors also proposed some modified prediction models. Saxena et al[5] proposed a new fuzzy time series prediction model based on inverse fuzzy numbers and they found that the prediction accuracy of average prediction error rate was very high. For example, they found that the value of average value of forecasting error rate (AFER) and mean square error (MSE) was $0.3406 \%$ and 9169 respectively when they analyzed the prediction of enrollment in University of Alabama. Wang et al [6][7][8][9][10] modified prediction model of inverse fuzzy number, which simplified calculation process and advanced the prediction accuracy in some cases. For example, Wang found that the value of AFER and MSE was $0.1705 \%$ and 1121 respectively based their modified prediction model. In our paper, we further modified the prediction model in [6] and called it fuzzy time series forecasting models based on difference and difference of difference (DDD). We defined the ratio of tourism income in the tertiary industry in the same period of 2005-2015 in Hainan province as proportion of possession of tertiary industry. In this paper, we analyzed prediction of proportion of possession in the period of 2005-2015 in Hainan province based on DDD. Fuzzy prediction accuracy of historical data was very high and value of AFER and MSE was $0.0842 \%$ and 0.00188 respectively. In addition, DDD can also predict unknown data of proportion, which indicated that DDD was better time series forecasting model.

\section{Prediction Model of DDD}

Establishment of Prediction Formula of DDD.

Prediction of DDD:

$$
C_{h}=K_{h-1}+A_{h-1}+\frac{0.002+1}{\frac{0.002}{A_{h-1}}+\frac{1}{B_{h}}}
$$


$\mathrm{C}_{\mathrm{h}}$ represents forecasting value of proportion of possession in "h" year; $K_{h-1}$ represents proportion of h-1 year, $A_{h-1}$ difference of proportion of possession in h-1 year; $B_{h}$ represents difference in difference of proportion of possession in h year; 0.002 represents membership of difference of $A_{h-1}$ of difference of proportion of possession in h-1 year.

\section{Application of DDD.}

First step: inputting of historical datas; second step: establishing universe of discourse of propprtion; third step: establishing predictiong formulas-(1) of DDD;forth step: prediting the proportion of possession of historical datas using DDD; fifth step: prediting the proportion of possession of unknown datas using DDD.

\section{Proportion of Possession in Tertiary Industry.}

Calculation formula of proportion of possession about tertiary industry was discribed in following:

$$
\mathrm{K}_{\mathrm{h}}=\left(\mathrm{H}_{\mathrm{h}} / \mathrm{D}_{\mathrm{h}}\right) * 100 \% \text {. }
$$

$\mathrm{H}_{\mathrm{h}}$ represents tourism income of $\mathrm{h}$ year; $\mathrm{D}_{\mathrm{h}}$ represents tertiary industry of h year.

Normally, rising of proportion of possession in tertiary industry indiactes that real estate develops rapidly; decling of proportion of possession in tertiary industry indicates that toruism develops rapidly. Development of real estate would be in a relatively period when it develops at certain stage, but develpment of tourism has larger space for growth. In presents, tourism is in a period of rapid growth in Hainan province.

\section{Precdiction of Proportion of Possession in 2005-2015 in Hainan Province}

Data of tourism income and tertiary industry in the perion of 2005-2015 in Hainan province was shown in Table-1.

Table 1 Proportion of possession of tourism income in sevince industry in the periond of 2005-2015 in Hainan province.

\begin{tabular}{cccc}
\hline Year & $\begin{array}{l}\text { Tourism income } \\
\text { (Billion Yuan)/ } \mathrm{H}_{\mathrm{h}}\end{array}$ & $\begin{array}{l}\text { Income of tertiary industry(Billion } \\
\text { Yuan)/ } \mathrm{D}_{\mathrm{h}}\end{array}$ & $\begin{array}{l}\text { Proportion } \\
\text { possession/ } \mathrm{K}_{\mathrm{h}}(\%)\end{array}$ \\
\hline & & & \\
2005 & 125.05 & 377.17 & 33.1548 \\
2006 & 141.43 & 433.57 & 32.6199 \\
2007 & 171.37 & 528.84 & 32.4049 \\
2008 & 192.33 & 643.47 & 29.8895 \\
2009 & 211.72 & 748.59 & 28.2825 \\
2010 & 257.63 & 953.67 & 27.0146 \\
2011 & 324.04 & 1148.93 & 28.2036 \\
2012 & 379.12 & 1339.53 & 28.3025 \\
2013 & 428.56 & 1644.14 & 26.0659 \\
2014 & 484.98 & 1815.23 & 26.7173 \\
2015 & 572.49 & 1971.81 & 29.0337 \\
\hline
\end{tabular}

\section{Establishing Universe of Discoursed of Historical Datas.}

Universe of discoursed of proportion of possession was set up based on the data of table-1:

$K=\left\{K_{2005}=33.1548, K_{2006}=32.6199, \ldots, K_{2014}=26.7173, K_{2015}=29.0337\right\}$.

Universe of discoursed of difference of proportion of possession was set up based on the formula of $\mathrm{Bh}=\mathrm{Kh}-\mathrm{Kh}-1$ :

$\mathrm{B}=\left\{\mathrm{B}_{2006}=-0.5349, \mathrm{~B}_{2007}=-0.2150, \ldots, \mathrm{B}_{2014}=0.6514, \mathrm{~B}_{2015}=2.3164\right\}$.

Universe of discoursed of difference in difference of proportion of possession was set up based on the formula of $\mathrm{Ah}=\mathrm{Bh}-\mathrm{Bh}-1$ :

$\mathrm{A}=\left\{\mathrm{A}_{2007}=0.3199, \mathrm{~A}_{2008}=-2.3004, \ldots, \mathrm{A}_{2014}=0.2 .8880, \mathrm{~A}_{2015}=1.6650\right\}$.

All above universes of discoursed were shown in Table-2. 
Table 2 Proportion of possession of tourism income in tertiary industry in the perion of 2005-2015 in Hainan province based on DDD.

\begin{tabular}{|c|c|c|c|c|c|c|}
\hline Year & $\begin{array}{l}\text { Proportion of } \\
\text { possession/ } \\
\mathrm{K}_{\mathrm{h}}(\%)\end{array}$ & $\begin{array}{l}\text { Differen } \\
\text { ce/B } B_{h}\end{array}$ & $\begin{array}{l}\text { Difference } \\
\text { in } \\
\text { difference/ } \\
\mathrm{A}_{\mathrm{h}}\end{array}$ & $\begin{array}{l}\text { Predicti } \\
\text { on } \\
\text { value/ } \\
\mathrm{C}_{\mathrm{h}} \\
\end{array}$ & $\left(C_{h}-K_{h}\right)^{2}$ & $\left|C_{h}-K_{h}\right| / K$ \\
\hline 2005 & 33.1548 & - & - & - & - & - \\
\hline 2006 & 32.6199 & -0.5349 & - & - & - & - \\
\hline 2007 & 32.4049 & -0.2150 & 0.3199 & 32.4059 & 0.000001 & 0.000031 \\
\hline 2008 & 29.8895 & -2.5154 & -2.3004 & 29.9332 & 0.001910 & 0.001462 \\
\hline 2009 & 28.2825 & -1.6070 & 0.9084 & 28.2850 & 0.000006 & 0.000088 \\
\hline 2010 & 27.0146 & -1.2679 & 0.3391 & 27.0154 & 0.000001 & 0.000030 \\
\hline 2011 & 28.2036 & 1.1890 & 2.4569 & 28.2181 & 0.000210 & 0.000514 \\
\hline 2012 & 28.3025 & 0.0989 & -1.0901 & 28.2983 & 0.000018 & 0.000148 \\
\hline 2013 & 26.0659 & -2.2366 & -2.3355 & 25.9452 & 0.014568 & 0.004631 \\
\hline 2014 & 26.7173 & 0.6514 & 2.8880 & 26.7306 & 0.000177 & 0.000498 \\
\hline 2015 & 29.0337 & 2.3164 & 1.6650 & 29.0285 & 0.000027 & 0.000179 \\
\hline AFER & & & & & & $0.0842 \%$ \\
\hline MSE & & & & & 0.001880 & \\
\hline
\end{tabular}

Establishment of prediction formula of DDD as formula-(1).

Prediction of Proportion of Possession of Tertiary Industry in 2005-2015 in Hainan Province Based on DDD.

Calculation results of proportion of possession were shown in Table-2 using the formula-(1). We found that value of AFER and MSE was $0.0842 \%$ and 0.00188 respectively from Table-1, which indicating high prediction accuracy.

Prediction of Unknown Proportion of Possession of Tertiary Industry in 2016-2018 in Hainan Province Based on DDD.

When we analyzed prediction value of unknown tourism income in 2016, we can not calculate directly the prediction value of proportion of possession in 2016 using the formula-(1) because the value of difference in difference $\left(\mathrm{A}_{2016}\right)$ of 2016 was unknown. So difference in difference $\left(\mathrm{A}_{2016}\right)$ was provided additionally and was marked as $\mathrm{A}^{+}{ }_{2016}$. Parameters of $\mathrm{B}_{2014}$ and $\mathrm{A}_{2015}$ of prediction value of proportion of possession in 2015 were corrected and value of error rate between forecasting value and real date was less than $1 \%$.

Correction process of $\mathrm{B}_{2014}$ and $\mathrm{A}_{2015}$ was following:

$\mathrm{A}^{+}{ }_{2016}=\mathrm{A}_{2015}+\mathrm{B}_{2014}-\mathrm{B}_{2015}=1.6650+0.6514-2.3146=0.0018$

$\mathrm{B}_{2014}$ was modified to $\mathrm{B}_{2015}=2.1364$, we calculated formula-(1) using $\mathrm{A}^{+}{ }_{2016}=0.0018$ and $\mathrm{K}_{2014}=26.7173$, and got the modified prediction value (29.0355) of proportion of possession in 2015 . In addition, the value of forecasting error rate was $0.0062 \%$, which was less than $1 \%$. The above results were shown in Table-3.

Table 3 Prediction of unknown proportion of possession in 2016-2018 in Hainan province based on DDD-(4-3-1).

\begin{tabular}{lllllll}
\hline Year & $\begin{array}{c}\text { Real value } \\
\text { proportion } \\
\text { possession } / \mathrm{K}_{\mathrm{h}}(\%)\end{array}$ & $\begin{array}{c}\text { of } \\
\text { of }\end{array}$ & $\begin{array}{c}\text { Prediction } \\
\text { value/ } \mathrm{C}_{\mathrm{h}}\end{array}$ & $\begin{array}{c}\text { Difference } \\
/ \mathrm{B}_{2005}\end{array}$ & $\begin{array}{c}\text { Difference in } \\
\text { difference/ } \\
\mathrm{A}^{+}{ }_{2016}\end{array}$ & $\begin{array}{c}\text { Growing } \\
\text { percentage than } \\
\text { previous year/\% }\end{array}$ \\
\hline 2015 & 29.0337 & 29.0355 & 2.3164 & - & 0.0062 \\
2016 & & 31.3519 & 2.3164 & 0.0018 & 7.9845 \\
2017 & & 33.6701 & 2.3164 & 0.0018 & 7.3941 \\
2018 & & 35.9883 & & 0.0018 & 6.8850 \\
\hline
\end{tabular}


We calculated formula-(1) using $\mathrm{B}_{2015}=2.1364, \mathrm{~A}^{+}{ }_{2016}=0.0018, \mathrm{~K}_{2015}=29.0337$, and got the prediction value(29.0355) of proportion of possession in 2016 and the growing percentage(7.9845\%) than previous year. Using same calculating method, we found that the prediction value of proportion of possession of 2017 and 2018 was 33.6701 and 35.9883 respectively, and the growing percentage of 2017 and 2018 was $7.3941 \%$ and $6.8850 \%$ respectively. All above calculation results were shown in Table-3.

\section{Conclusion}

Prediction formula of DDD has simple structure and high forecasting accuracy using historical data of time series. For example, the value of AFER and MSE was $0.0842 \%$ and 0.00188 respectively when proportion of possession of tourism income in tertiary industry in 2005-2015 in Hainan province based on DDD. Whatsmore, DDD can also predict well unknown data, which was a research hotspots in future.

\section{Acknowledgments}

This research was funded by the Natural Science Foundation of Hainan Province (Project No. 714283, 114011) and Coorperative Project between Sanya City and University (Project No. 2015YD34) and Youth Fund Project of Qiongzhou University(Project No. QYQN201434).

\section{References}

[1] Zadeh LA. Fuzzy set [J].Fuzzy Sets and Systems, 1965,8:338-353.

[2] Song Q, Chissom BS. Forecasting enrollments with fuzzy time series [J].Fuzzy Sets and Systems, 1993,54: 269-277.

[3] Song Q, Chissom BS. Forecasting enrollments with fuzzy time series-Part II[J].Fuzzy Sets and Systems, 1994.62:1-8.

[4] Song Q, Chissom BS. Forecasting enrollments with fuzzy time series-Part I[J].Fuzzy Sets and Systems, 1993.54:1-9.

[5] Preetika Saxena, Kalyani Sharma, Santhosh Easo. Forecasting enrollments based on fuzzy time series with higher forecast accuracy rate [J]. Int. J. Computer Technology\& Applications, 2012,3(3): 957-961.

[6] Hongxu Wang, Jianchun Guo, Hao Feng, et al. An improved forecasting model of fuzzy time series. Applied Mechanice and Materials, 2014.678:64-69.

[7] Hongxu Wang, Jianchun, Guo Hao Feng, Fujin Zhang. A new model of forecast enrollment using fuzzy time series. Education Management and Management Science,2014 International Conference on Education Management and Management Science (ICEMMS 2014), 7-8 August,2014,Tianjin, China, 2014.95-98.

[8] HongXu Wang, JianChun Guo, Hao Feng, HaiLong Jin.A fuzzy time series forecasting model based on percentages. $2^{\text {nd }}$ International Conference on Frontiers in Computer Education (ICFCE2014), December 24-25, 2014, Wuhan, China. 1 ICT IN EDUCATION. Frontiers in Computer Education, 2014.11-14.

[9] Hongxu Wang, Jianchun Guo, Hao Feng, and Hailong Jin. A new forecasting model of fuzzy time series. Applied Mechanice and Materials, 2014,678:59-63.

[10] HongXu Wang, JianChun Guo, Hao Feng, HaiLong Jin. A fuzzy time series forecasting model based on data differences. $2^{\text {nd }}$ International Conference on Frontiers in Computer Education (ICFCE2014), December 24-25, 2014, Wuhan, China. 1 ICT IN EDUCATION. Frontiers in Computer Education,2014.15-18. 